\title{
An internet-based study on the relation between disgust sensitivity and emetophobia
}

Citation for published version (APA):

van Overveld, M., de Jong, P. J., Peters, M. L., van den Hout, W. B., \& Bouman, T. K. (2008). An internetbased study on the relation between disgust sensitivity and emetophobia. Journal of Anxiety Disorders, 22(3), 524-531. https://doi.org/10.1016/j.janxdis.2007.04.001

Document status and date:

Published: 01/01/2008

DOI:

10.1016/j.janxdis.2007.04.001

Document Version:

Publisher's PDF, also known as Version of record

Document license:

Taverne

Please check the document version of this publication:

- A submitted manuscript is the version of the article upon submission and before peer-review. There can be important differences between the submitted version and the official published version of record.

People interested in the research are advised to contact the author for the final version of the publication, or visit the DOI to the publisher's website.

- The final author version and the galley proof are versions of the publication after peer review.

- The final published version features the final layout of the paper including the volume, issue and page numbers.

Link to publication

\footnotetext{
General rights rights.

- You may freely distribute the URL identifying the publication in the public portal. please follow below link for the End User Agreement:

www.umlib.nl/taverne-license

Take down policy

If you believe that this document breaches copyright please contact us at:

repository@maastrichtuniversity.nl

providing details and we will investigate your claim.
}

Copyright and moral rights for the publications made accessible in the public portal are retained by the authors and/or other copyright owners and it is a condition of accessing publications that users recognise and abide by the legal requirements associated with these

- Users may download and print one copy of any publication from the public portal for the purpose of private study or research.

- You may not further distribute the material or use it for any profit-making activity or commercial gain

If the publication is distributed under the terms of Article $25 \mathrm{fa}$ of the Dutch Copyright Act, indicated by the "Taverne" license above, 


\title{
An internet-based study on the relation between disgust sensitivity and emetophobia
}

\author{
Mark van Overveld ${ }^{\mathrm{a}, *}$, Peter J. de Jong ${ }^{\mathrm{b}}$, Madelon L. Peters ${ }^{\mathrm{a}}$, \\ Wiljo J.P.J. van Hout ${ }^{\mathrm{b}}$, Theo K. Bouman ${ }^{\mathrm{b}}$ \\ ${ }^{a}$ Department of Clinical Psychological Science, Maastricht University, P.O. Box 616, 6200 MD Maastricht, the Netherlands \\ ${ }^{\mathrm{b}}$ Department of Clinical and Developmental Psychology, University of Groningen, Grote Kruisstraat 2/1, \\ 9712 TS Groningen, the Netherlands
}

Received 4 December 2006; received in revised form 4 April 2007; accepted 5 April 2007

\begin{abstract}
In the etiology of disgust-relevant psychopathology, such as emetophobia (fear of vomiting), two factors may be important: disgust propensity, i.e., how quickly the individual experiences disgust, and disgust sensitivity, i.e., how negatively does the individual evaluate this disgust experience [van Overveld, W. J. M., de Jong, P. J., Peters, M. L., Cavanagh, K., \& Davey, G. C. L. (2006). Disgust propensity and disgust sensitivity: separate constructs that are differentially related to specific fears. Personality and Individual Differences, 41, 1241-1252]. Hence, the current study examines whether emetophobic participants display elevated levels of disgust propensity and sensitivity, and whether these factors are differentially related to emetophobia.

A group of emetophobic members of a Dutch website on emetophobia $(n=172)$, and a control group $(n=39)$ completed an internet survey containing the Emetophobia Questionnaire, Disgust Propensity and Sensitivity Scale-Revised, Disgust Scale, and Disgust Questionnaire.

Results showed that the emetophobic group displayed significantly elevated levels of both disgust propensity and disgust sensitivity compared to the control group. Most importantly, disgust sensitivity consistently was the best predictor of emetophobic complaints.
\end{abstract}

(C) 2007 Elsevier Ltd. All rights reserved.

Keywords: Emetophobia; Fear of vomiting; Disgust; Internet survey; Specific phobias

Although estimates on the prevalence of emetophobia (fear of vomiting) range between 1.7 and $3.1 \%$ for men, and 6 and $7 \%$ for women (van Hout \& Bouman, 2006; Philips, 1985), only few empirical data are available regarding this peculiar disorder (Boschen, 2007). Emetophobia is defined as fear of vomiting and

\footnotetext{
* Corresponding author. Tel.: +31 43 3881608; fax: +31433884155 .

E-mail address: M.vanOverveld@DMKEP.Unimaas.nl (M. van Overveld).
}

is frequently interpreted as a comorbid disorder in several forms of psychopathology, like social phobia (Marks, 1987), agoraphobia (Pollard, Tait, Meldrum, Dubinsky, \& Gall, 1996), or panic disorder (Lydiard, Laraia, Howell, \& Ballenger, 1986). However, it has been observed that emetophobia does not fit easily into any of these categories (Lelliott, McNamee, \& Marks, 1991). This observation is further sustained by case studies in which emetophobia appears the primary, rather than secondary diagnosis (e.g., Dattilio, 2003; Moran \& O’Brien, 2005; Ritow, 1979), as well as the 
observation that the appearance of comorbid disorders starts only after the onset of emetophobia (Lipsitz, Fyer, Paterniti, \& Klein, 2001).

The three most common central themes relevant to people characterized by emetophobia are fear of vomiting themselves, fear of seeing others vomit, or fear of vomiting in the presence of other people (van Hout \& Bouman, 2006; van Hout, Oude Lansink, \& Bouman, 2005; Veale \& Lambrou, 2006). People with emetophobia tend to avoid all stimuli that may even be slightly related to vomiting. This may range from avoiding the use of the word 'vomit' to eating in public, or even pregnancy out of fear of becoming nauseous (Massop, 2005).

As vomit itself is one of the few universally accepted disgust stimuli (Rozin, Haidt, \& McCauley, 2000), it seems reasonable to suspect that disgust and fear of contamination are somehow involved in emetophobia. Disgust may be involved in the etiology and maintenance of psychopathology in various ways. First, it has been argued that certain stimuli are characterized by high levels of contamination potency. Objects that are regarded highly disgusting, and that are capable of engaging physical contact with the individual, tend to be evaluated as having high contamination potency. For example, spider phobics consider spiders to be highly disgusting objects with a high contamination potency (Mulkens, de Jong, \& Merckelbach, 1996; Thorpe \& Salkovskis, 1998). Consequently, research indicated that indeed spider phobia may be better understood as a fear of physical contact and contamination with a disgusting object (de Jong \& Muris, 2002).

A second pathway in which disgust may be involved in psychopathology may be that some people are extremely sensitive to the experience of disgust and contamination. Recent work showed that for the development of psychopathology, it may not only be relevant how often people experience disgust (disgust propensity), but also whether they evaluate this experience negatively (i.e., disgust sensitivity; van Overveld, de Jong, Peters, Cavanagh, \& Davey, 2006). Recent reports indeed suggest that emetophobic individuals tend to avoid being disgusted, mostly in an attempt to avoid related feelings of nausea (Boschen, 2007; Lipsitz et al., 2001; Veale \& Lambrou, 2006).

The primary aim of the present study was to determine whether individuals with emetophobia display elevated levels of both disgust propensity and disgust sensitivity. The present study will therefore not only include more traditional disgust indices, i.e., the Disgust Questionnaire (DQ; Rozin, Fallon, \& Mandell, 1984) and the Disgust Scale (DS; Haidt, McCauley, \&
Rozin, 1994), but also the newly devized Disgust Propensity and Sensitivity Scale-Revised (DPSS-R; van Overveld et al., 2006). The latter is the only instrument to date that covers disgust sensitivity in addition to disgust propensity. Similar to other disorders in which disgust is presumed to be involved, i.e., spider fear and blood fear (van Overveld et al., 2006), it was hypothesized that both levels of disgust propensity and disgust sensitivity would be elevated in emetophobic individuals compared to control participants. Additionally, recent findings indicated that disgust propensity and disgust sensitivity may be differentially involved in various types of psychopathology (van Overveld et al., 2006). Disgust sensitivity was found to be most strongly involved in disorders in which disgust rather than fear is the dominant emotion (e.g., blood phobia; van Overveld et al., 2006). On the basis of evidence suggesting that emetophobic individuals tend to avoid being disgusted, we hypothesized that enhanced disgust sensitivity would be more strongly involved in emetophobia than heightened levels of disgust propensity.

\section{Methods}

\subsection{Participants}

All members $(n=348)$ of a website for people with emetophobic complaints were invited to participate in the present internet study through a newsletter via e-mail and via advertisements on the website www. emetofobie.nl and in newsletters to its members. However, not all people on the member list were still active members of the site. Furthermore, although most members of this particular website are characterized by emetophobic complaints, successfully treated emetophobics also tend to remain a member of the site. Therefore, it was stressed in the advertisements that in order to participate, one should still have emetophobic complaints. Additionally, all emetophobic participants were encouraged to invite someone in their close personal surroundings (e.g., relatives, friends, partner) to complete the survey as well. Participants were instructed that this person should preferably match the emetophobic participant in age and gender. Furthermore, it was emphasized that these people should be free of any emetophobic complaints. Of the emetophobic group, $32 \%$ were able to recruit a nonemetophobic participant. These control participants had to contact the experimenter themselves via email, to be able to participate. Consequently, both experimenter and participants were generally aware to which group 
the participants were assigned. Further, prior to the administration of the questionnaires, participants indicated whether they had a fear of vomiting (yes/ no). However, although everybody was allowed to participate, participants did not know whether they genuinely qualified as emetophobic or as control, as this was generally determined only after completion of all questionnaires by comparing the self-diagnosis with group membership. Since $40 \%$ of all the members of the website participated, this resulted in a self-diagnosed emetophobic group ( $n=138 ; 16$ men, 122 women) with a mean age of 25.4 years (S.D. $=8.2$; range: $15-68$ years). Of the emetophobic individuals, $4.5 \%$ completed only primary education (i.e., elementary school; approximately 6-8 years of education), $67.7 \%$ completed secondary education (i.e., high school; approximately 10-14 years of education), and $27.8 \%$ completed tertiary educational levels (i.e., college or university; approximately 14-20 years of education). The control group ( $n=43 ; 3$ men, 40 women) had a mean age of 24.7 years (S.D. $=5.9$; range: $15-43$ years). Furthermore, $5.1 \%$ of the control group completed primary education, 59\% completed secondary education, and $35.9 \%$ completed tertiary educational levels.

\subsection{Materials}

\subsubsection{Disgust Propensity and Sensitivity Scale- Revised (DPSS-R; van Overveld et al., 2006)}

The 16-item DPSS-R measures disgust propensity (i.e., to what extent do participants experience disgust in any given situation) and sensitivity (i.e., how horrid do participants consider this disgust experience). On a scale from 1 (='never') to 5 (='always'; range: 16-80), participants rate a series of positions on both how often they experience specific (bodily) symptoms related to disgust (e.g., 'I screw up my face in disgust.'), and to what extent these symptoms are upsetting to them (e.g., 'When I feel disgusted, I worry that I might pass out.'). The DPSS-R and its subscales appear internally consistent (alpha coefficients $>0.71$; van Overveld et al., 2006). In the present study, internal consistency was high for both propensity and sensitivity (both alphas: 0.88).

\subsubsection{The disgust and contamination sensitivity questionnaire (DQ; Rozin et al., 1984)}

This 24-item questionnaire examines the tendency of the participants to reject desirable and perfectly edible food items, when they have been contaminated with disgusting stimuli. On a scale from 1 to $9(1=$ 'not at all', $9=$ 'very much'; range 24-216, where high scores reflect low disgust propensity), participants indicate their willingness to eat certain food items after it has been contaminated (e.g., 'Imagine a bowl of a particular type of soup that you like very much. How much would you like to eat that soup from a thoroughly washed used dog bowl?'). The DQ is internally consistent (alpha $=0.72-$ 0.86, Davey, 1994; 0.80, Mulkens et al., 1996).

\subsubsection{Disgust Scale (DS; Haidt et al., 1994)}

The DS contains 32 items, and examines an individuals' disgust propensity, i.e., the tendency to experience disgust for eight types of disgust elicitors: Animals, Bodily Products, Body-Envelope Violations, Death, Food, Hygiene, Sex, and Sympathetic Magic. The first half of the questionnaire has true/false type questions (e.g., 'I might be willing to try eating monkey meat, under some circumstances.'), the second half has to be rated on a 3-point Likert-scale from 0 (="not disgusting at all') to 2 (='extremely disgusting') (e.g., 'You hear about an adult woman who has sex with her father.'). Thus, a total score (range: 0-32) as well as eight subscale scores can be obtained. Previous research indicates that although alphas for the subscales are low (0.34-0.64; Haidt et al., 1994), alpha is high for the total score (0.84; Haidt et al., 1994).

\subsubsection{Emetophobia Questionnaire (EQ; Bouman \& van Hout, in preparation)}

The EQ is a 115 -item scale developed within a larger research project in which the University of Groningen and Maastricht University participate (Bouman, \& van Hout, in preparation). The questionnaire contains items on various aspects of emetophobia, such as worrying about vomiting, bodily sensations, fear of vomiting (e.g., 'I am afraid of becoming nauseous.'), the avoidance of vomit-related situations (e.g., 'I avoid being around people who look as if they may be sick.'), and the consequences of emetophobia in daily life (e.g., 'Because of my fear of vomiting, I have lost weight.'). Items have to be answered on a Likert-scale from 1 (='not at all') to 5 (='very much'). For the 16 items referring to the consequences of emetophobia, an additional answer category was added $(0=$ 'not applicable') for participants without emetophobic fears. In this study, four scales of this questionnaire were used, i.e. the total score (98 items, scoring range: 98-575; alpha $=0.97$ ), and three a priori subscales, notably emetophobic complaints (68 items; range: 68-340; alpha $=0.97$ ), emetophobic avoidance (30 items; scoring range: $30-150$; alpha $=0.94)$, emetophobia consequences (16 items; scoring range: 0-80; alpha $=$ $0.96)$. 


\subsection{Procedure}

People who indicated to be willing to participate received an individual login number and password, with which they could $\log$ in to the University server. Once logged in, all participants completed a few biographical questions on age, sex, and educational level. In addition, they were asked to indicate whether they had a fear of vomiting. After this, participants received Dutch versions of the DPSS, EQ, DQ, and DS. Questionnaires were always administered in that particular order. The questionnaires were completed and analyzed anonymously. No reward was given upon completion of the questionnaires.

\section{Results}

\subsection{Descriptive statistics}

The results of two members of the website were excluded based on their self-diagnosis, on which they indicated that they did not have a fear of vomiting. The results of four participants from the control group were also excluded from further analyses, as they indicated that they had (some) fear of vomiting. Further, data of one person in the emetophobic group and two people in the control group were removed because they dropped out before completing $10 \%$ on the first two questionnaires, the EQ or the DPSS. Thus, a sample of 133 people in the emetophobia group and 39 people in the control group remained.

As the inclusion criterion to be assigned to either of the two groups relied solely on self-diagnosis, it is important to establish whether the classification appears to be valid. This was done by studying the difference in scores on the EQ of the emetophobic group compared to the control group. Mean scores on the EQ indicated that indeed the emetophobic and the control groups scored very differently with respect to emetophobic complaints. Only the two highest scoring individuals of the control group (mean EQ-scores 228 and 261, respectively) had overlapping scores with the emetophobic group, and even they both fell within the first decile of the scores of the emetophobic group. Furthermore, one person in the emetophobic group scored considerably lower than the rest of the participants in the emetophobic group (EQ-score: 173, while the second lowest person scored 239), and it therefore could be questioned whether that person can be considered emetophobic on the basis of the EQ-scores. Nevertheless, the results of these persons were included in the group to which they assigned themselves. Additionally, the ROC-curve provides a trade-off between true positive rate (sensitivity) and false positive rate (1specificity) of classified individuals. Based on this curve, a cut-off score can be abstracted for the EQ. Here, results showed that when placing the cut-off score at a score greater than or equal to 233.50 , a sensitivity of 0.99 and a 1 -specificity of 0.03 would be obtained. This would be very acceptable, and it confirms that our two groups appear distinct with regard to emetophobic complaints.

Next, mean scores on all questionnaires were calculated for both the emetophobic and the control group. Then, one-way ANOVAs were used to determine whether these scores differed significantly between groups. Table 1 shows that, as expected, the emetophobic participants were indeed characterized by significantly more emetophobic complaints and vomit-related avoidance behavior (as indexed by EQComplaints and EQ-Avoidance and EQ-Consequences). Furthermore, compared to the control group,

Table 1

Mean scores and standard deviations for the emetophobic and the control group

\begin{tabular}{lcccc}
\hline Indices & Emetophobic group & Control group & $F(1,171)$ & $p$ \\
\hline EQ total & $360.21(64.23)$ & $176.54(29.24)$ & 299.27 & $\eta^{2}$ \\
$\quad$ Complaints & $206.95(36.89)$ & $104.48(24.48)$ & 265.25 & $<0.001^{* *}$ \\
Avoidance & $87.55(18.21)$ & $49.97(8.89)$ & 154.54 & $<0.001^{* *}$ \\
Consequence & $47.75(14.19)$ & $0.77(3.40)$ & 418.77 & $<0.001^{* *}$ \\
DS total & $18.44(4.93)$ & $15.49(4.37)$ & 11.09 & $<0.61$ \\
DQ total & $107.76(38.87)$ & $138.00(35.08)$ & 18.86 & 0.48 \\
DPSS-Propensity & $25.18(4.98)$ & $18.54(4.01)$ & 58.27 & $<0.72$ \\
DPSS-Sensitivity & $25.44(5.28)$ & $13.41(3.64)$ & 176.99 & $<0.01^{* *}$ \\
Valid $n$ & 133 & 39 & & $<0.01^{* *}$ \\
\hline
\end{tabular}

Note. Standard deviations are described in parentheses. Abbreviations: Emetophobic Questionnaire (EQ), Disgust Scale (DS), Disgust Questionnaire (DQ), Disgust Propensity and Sensitivity Scale-Revised (DPSS-R).

*** Significant at $p<0.01$. 
Table 2

Correlations between the Emetophobia Questionnaire and the disgust indices

\begin{tabular}{|c|c|c|c|c|}
\hline & EQ-total & EQ-Complaints & EQ-Avoidance & EQ-Consequences \\
\hline DS & $0.45^{* *}$ & $0.47^{* * *}$ & $0.48^{* *}$ & $0.31^{* *}$ \\
\hline DQ & $-0.47^{* *}$ & $-0.46^{* *}$ & $-0.47^{* *}$ & $-0.40^{* *}$ \\
\hline DPSS-Propensity & $0.70^{* *}$ & $0.71^{* *}$ & $0.66^{* *}$ & $0.60^{* *}$ \\
\hline DPSS-Sensitivity & $0.86^{* *}$ & $0.86^{* *}$ & $0.79^{* *}$ & $0.80^{* *}$ \\
\hline Valid $n$ & & & & 172 \\
\hline
\end{tabular}

Note: Abbreviations: Emetophobic Questionnaire (EQ), Disgust Scale (DS), Disgust Questionnaire (DQ), Disgust Propensity and Sensitivity ScaleRevised (DPSS-R).

*** Significant at $p<0.01$.

the emetophobic group displayed significantly elevated levels of disgust propensity (as indexed by the DQ, DS, and DPSS-Propensity), as well as disgust sensitivity (as indexed by DPSS-Sensitivity).

\subsection{Correlations between disgust and emetophobia}

Table 2 displays the Bivariate Pearson's $p-m$ correlations between the subscales of the EQ (EQComplaints and EQ-Avoidance) and the disgust indices (DPSS, DS, DQ) in the entire sample. All correlations between the level of emetophobic complaints (EQComplaints) and either disgust propensity (DQ, DS, DPSS-Propensity) or disgust sensitivity (DPSS-Sensitivity) were moderate to high and statistically significant. The correlations between EQ-Avoidance and all disgust indices revealed an identical pattern. The correlation between the DQ and the EQ was negative, yet, this is due to the scaling of the DQ (which has an inverse scorings format where low total scores reflect higher disgust propensity).

\subsection{Contribution of disgust to emetophobia}

Hierarchical regression analyses $($ method $=$ Enter) were performed to determine the relative contributions of disgust propensity and disgust sensitivity to emetophobia, and whether the disgust sensitivity component explains additional variance compared to disgust propensity. For these analyses, the scores on the EQ-Complaints or EQ-Avoidance were used as dependent variables. As predictor variables, scores on DPSSPropensity, DPSS-Sensitivity, DQ-total scores and DS-total scores were used. All participants were included in these analyses. In order to investigate whether both factors disgust propensity and disgust sensitivity contribute uniquely to emetophobia, in each analysis, disgust propensity measures (DQ, DS, DPSSR-Propensity) would be entered in the first step and the disgust sensitivity index (DPSS-R-Sensitivity) in the second step. A summary of the main statistics is displayed in Table 3.

For the EQ-total scores, in the first model containing only the propensity indexes only the DQ $(p<0.01)$ and DPSS-Propensity $(p<0.01)$ were significant predictors. However, when DPSS-Sensitivity was entered in the second step, DPSS-Sensitivity proved to be the single best predictor $(p<0.01)$. The disgust propensity indexes were no longer significant.

For EQ-Complaints, in the first step, the DQ $(p<0.01)$ and DPSS-Propensity $(p<0.01)$ were significant predictors. However, when DPSS-Sensitivity entered in the second step of the analysis, only DPSSSensitivity remained a significant predictor $(p<0.01)$.

For EQ-Avoidance, in the first step, the DQ $(p=0.01)$ and DPSS-Propensity $(p<0.01)$ were significant predictors, but when DPSS-Sensitivity entered in the second step, DPSS-Sensitivity was the single best predictor $(p<0.01)$.

Finally, for EQ-Consequences, in the first step, the DQ $(p<0.01)$ and DPSS-Propensity $(p<0.01)$ were significant predictors. When DPSS-Sensitivity entered in the second step, DQ and DPSS-Propensity were no longer significant, but DPSS-Sensitivity $(p<0.01)$ as well as the DS $(p<0.01)$ were significant predictors.

\section{Discussion}

The main findings can be summarized as follows: (a) the emetophobic group demonstrated elevated levels of both disgust propensity and disgust sensitivity, compared to the control group, (b) there was a strong interrelationship between the intensity of emetophobic complaints on the one hand and the levels of disgust propensity and disgust sensitivity on the other, (c) most important, disgust sensitivity proved consistently to be the single best predictor of the variance in scores on the EQ.

As expected, it was found that emetophobic individuals demonstrate more symptoms of vomit-related 
Table 3

Hierarchical regression analyses for the disgust indices as predictors of the Emetophobia Questionnaire (EQ) and its subscales

\begin{tabular}{lccrc}
\hline Questionnaire & $B$ & S.E. $B$ & \multicolumn{1}{c}{$\beta$} & $p$ \\
\hline Analysis 1: EQ-total & & & \\
Step 1: $R^{2}=0.55, F=63.38$, & $p<0.01$ & & \\
DQ & -0.46 & 0.16 & -0.19 & $<0.01^{* * *}$ \\
DPSS-P & 10.66 & 1.15 & 0.61 & $<0.01^{* *}$ \\
DS & 0.50 & 1.35 & 0.03 & 0.71 \\
Step 2: $R^{2}=$ & $0.77, F=151.83, p<0.01$ & & \\
DQ & -0.22 & 0.12 & -0.09 & 0.07 \\
DPSS-P & 1.50 & 1.11 & 0.09 & 0.18 \\
DS & -0.78 & 0.98 & -0.04 & 0.42 \\
DPSS-S & 10.50 & 0.85 & 0.78 & $<0.01^{* *}$
\end{tabular}

Analysis 2: EQ-Complaints

Step 1: $R^{2}=0.55, F=66.03, p<0.01$

$\begin{array}{lrlrc}\text { DQ } & -0.26 & 0.09 & -0.19 & <0.01^{* *} \\ \text { DPSS-P } & 6.05 & 0.65 & 0.61 & <0.01^{* *} \\ \text { DS } & 0.54 & 0.76 & 0.05 & 0.48\end{array}$

Step 2: $R^{2}=0.76, F=138.89, p<0.01$

$\begin{array}{lrrrc}\text { DQ } & -0.12 & 0.07 & -0.09 & 0.08 \\ \text { DPSS-P } & 1.00 & 0.64 & 0.10 & 0.12 \\ \text { DS } & -0.17 & 0.56 & -0.02 & 0.77 \\ \text { DPSS-S } & 5.80 & 0.49 & 0.75 & <0.01^{\text {** }}\end{array}$

Analysis 3: EQ-Avoidance

Step 1: $R^{2}=0.51, F=54.64, p<0.01$

$\begin{array}{lrrrr}\text { DQ } & -1.03 & 0.04 & -0.18 & 0.01^{*} \\ \text { DPSS-P } & 2.24 & 0.28 & 0.54 & <0.01^{\text {** }} \\ \text { DS } & 0.43 & 0.33 & 0.09 & 0.20\end{array}$

Step 2: $R^{2}=0.66, F=73.43, p<0.01$

$\begin{array}{lrrrr}\text { DQ } & -0.06 & 0.03 & -0.10 & 0.10 \\ \text { DPSS-P } & 0.44 & 0.31 & 0.11 & 0.17 \\ \text { DS } & 0.17 & 0.28 & 0.04 & 0.53 \\ \text { DPSS-S } & 2.07 & 0.24 & 0.65 & <0.01^{\text {*** }}\end{array}$

Analysis 4: EQ-Consequences

Step 1: $R^{2}=0.40, F=35.22, p<0.01$

$\begin{array}{lrrrc}\text { DQ } & -0.12 & 0.05 & -0.21 & <0.01^{\text {** }} \\ \text { DPSS-P } & 2.38 & 0.32 & 0.56 & <0.01^{\text {*** }} \\ \text { DS } & -0.47 & 0.38 & -0.10 & 0.22\end{array}$

Step 2: $R^{2}=0.66, F=117.77, p<0.01$

\begin{tabular}{lrllc} 
DQ & -0.06 & 0.04 & -0.10 & 0.10 \\
DPSS-P & -0.01 & 0.33 & -0.00 & 0.98 \\
DS & -0.80 & 0.29 & -0.17 & $<0.01^{\text {*** }}$ \\
DPSS-S & 2.74 & 0.25 & -0.83 & $<0.01^{\text {*** }}$ \\
\hline
\end{tabular}

Note: Abbreviations: Emetophobic Questionnaire (EQ), Disgust Scale (DS), Disgust Questionnaire (DQ), Disgust Propensity and Sensitivity Scale-Revised Propensity (DPSS-P), Disgust Propensity and Sensitivity Scale-Revised Sensitivity (DPSS-S).

* Significant at $p<0.05$.

*** Significant at $p<0.01$.

concerns than the control group. The emetophobic individuals were characterized by significantly more emetophobic complaints (e.g., worrying about vomiting or seeing others vomit), avoid vomit-related stimuli (e.g., the use of the word 'vomit' or standing near a drunk person) significantly stronger, and reported that fear of vomiting has a stronger impact on their daily life (e.g., experiencing guilt or shame) compared to the control group.

Furthermore, it was hypothesized that disgust may be involved in emetophobia. Recently, it was shown that for disgust-relevant complaints to emerge, it may not only be important how quickly and how often people experience disgust (disgust propensity), but more so whether they evaluate this experience negatively (i.e., disgust sensitivity; van Overveld et al., 2006). The present findings confirm the view that disgust sensitivity appears involved in disgust-relevant complaints. Most importantly, upon studying the relation between disgust sensitivity, disgust propensity and the Emetophobia Questionnaire, disgust sensitivity proved the single best predictor of the variance in scores on the EQ. Thus, from the data from the present research, it can be concluded that disgust sensitivity contributes more strongly than disgust propensity to emetophobia. This strengthens the previous postulation that the differential role of disgust propensity and disgust sensitivity may vary across disorders (van Overveld et al., 2006).

Future research should take several issues into account. First, research on emetophobia is presently lacking a standardized instrument to establish emetophobia. Thus, most studies use self-developed questionnaires (e.g., Bouman \& van Hout, in preparation; Lipsitz et al., 2001; Veale \& Lambrou, 2006). Consequently, the psychometric properties of these indices remain to be determined. This is particularly problematic, as this renders a comparison between studies more difficult. Future research should focus on developing a valid and reliable instrument for establishing emetophobic concerns.

Second, the present study did not use clinically established patients, but relied on self-diagnosis. However, most members of the site are treatmentseeking individuals, persons who have been in treatment or who are currently embarking in treatment. Moreover, results confirmed that the emetophobic group were indeed characterized by significantly elevated levels on a broad range of emetophobic concerns. This adds validity to the claim that these groups are indeed different with regard to emetophobic complaints. Nevertheless, it remains to be determined whether clinical populations would display similar elevated levels. Thus, future research should investigate whether similar results can be obtained in a sample comprized of patients with an established clinical diagnosis of emetophobia, compared to a non-clinical control group. 
Germane to this issue, the present study compared only non-clinical individuals to a self-diagnosed clinical group. Since the present study did not include a clinical comparison group with disgust-unrelated psychopathology, it remains to be seen whether disgust sensitivity has a unique relationship with vomiting fears. An important next step would be to test the specificity of the relationship between emetophobia and disgust sensitivity, e.g., by including clinical comparison groups (e.g., patients with disgust-unrelated psychopathology such as depression or chronic pain patients).

Third, in line with earlier studies, the gender distribution of emetophobic complaints was extremely skewed. Previously, an internet survey by Lipsitz et al. (2001) revealed that $89 \%$ of the emetophobic individuals were women, Veale and Lambrou (2006) found $97 \%$ of the emetophobic sample in his study to be women. Emetophobia appears to be found predominantly in young women who are relatively high educated. One explanation for this could be that disgust propensity is crucially involved. Research indicates that women are characterized by elevated levels of disgust propensity (Matchett \& Davey, 1991; Ware, Jain, Burgess, \& Davey, 1994), and that this may explain why disgust-relevant psychopathology is observed predominantly in women (Olatunji, Arrindell, \& Lohr, 2005; Olatunji, Sawchuk, Arrindell, \& Lohr, 2005). Even so, compared to contamination-related $\mathrm{OCD}$, or other disgust-relevant disorders, e.g., blood phobia, the gender distribution of emetophobia appears extremely skewed. Alternatively, women may just be more interested in websites on health issues than men (Buchanan \& Smith, 1999), and search for them more actively. Additionally, since women in this study were young, they may simply have better accessibility to the internet. For example, $70 \%$ of people between 20 and 50 years use the internet, whereas this number decreases dramatically in older people (Hayslett $\&$ Wildemuth, 2004). Yet, using non-web-based studies, it was still reported that people with vomit phobias are young women (Himle, McPhee, Cameron, \& Curtis, 1989; Veale \& Lambrou, 2006). However, as the number of studies is scarce at present, future studies should determine whether the skewed age and gender distributions are consistently observed in emetophobia.

Fourth, if disgust sensitivity indeed uniquely contributes to emetophobia, it would be interesting to investigate whether inflated levels of disgust sensitivity are merely an epiphenomenon of emetophobia or whether there may be a causal relationship. One way to investigate this issue would be to conduct a longitudinal study, in which participants who are free of any disgustrelevant psychopathological complaints but who are characterized by either high or low levels of disgust sensitivity at the start of the study will be measured for a number of years. As the age range of 13-17 years appears the critical period in which emetophobic complaints start for most emetophobics (Lelliott et al., 1991; van Hout \& Bouman, 2006; van Hout et al., 2005), it would be advisable to study participants during this vulnerability period to examine whether increased levels of disgust sensitivity render emetophobic or other disgust-relevant complaints (e.g., spider phobia, blood, phobia, contamination-related OCD) more likely to develop.

Additionally, the current study does have certain apparent limitations. First, the current study relied fully on self-report indices. Moreover, as participants were generally aware of their group membership, the observed relationship between disgust propensity, disgust sensitivity and emetophobia may thus have become inflated. Therefore, it should be investigated whether similar relationships can be found when another type of research methodology is applied, for example, whether emetophobic individuals display disgust-relevant physiological reactivity upon confrontation with vomit-related stimuli compared to healthy controls (e.g., activity of the disgust specific m. levator labii; de Jong, Peters, \& Vanderhallen, 2002) or are characterized by stronger disgust and contamination related associations for vomit-related situations and stimuli (e.g., on the Implicit Association Test). Second, as the present study is cross-sectional, no causal inferences can be made. Thus, although it was concluded that disgust sensitivity contributes stronger to emetophobia than disgust propensity, it remains to be determined whether inflated levels of disgust sensitivity are causally related to emetophobia, or are merely an epiphenomenon of fear of vomiting.

In sum, the present findings further sustain the notion that there may be a distinct subgroup of patients with an intense fear of vomiting (e.g., Lipsitz et al., 2001; Veale \& Lambrou, 2006). Most importantly, the present findings extended earlier work by demonstrating that disgust sensitivity, rather than disgust propensity, may be involved in emetophobia. Nevertheless, future studies could benefit significantly from both the development of a valid and reliable index for emetophobia, and the inclusion of patients with emetophobia and a clinical comparison groups.

\section{Acknowledgements}

The authors wish to express their gratitude to Margaret Massop, administrator of the website www.emetofobie.nl and its members, for their participation in this research. 


\section{References}

Boschen, M. J. (2007). Reconceptualizing emetophobia: a cognitivebehavioral formulation and research agenda. Journal of Anxiety Disorders.

Bouman, T. K., \& van Hout, W. J. P. J. (in preparation). A questionnaire for emetophobia.

Buchanan, T., \& Smith, J. L. (1999). Using the internet for psychological research: personality Ttesting on the World Wide Web. British Journal of Psychology, 90, 125-144.

Dattilio, F. M. (2003). Emetic exposure and desensitization procedures in the reduction of nausea and a fear of emesis. Clinical Case Studies, 2, 199-210.

Davey, G. C. L. (1994). Self-reported fears to common indigenous animals in an adult UK population: the role of disgust sensitivity. British Journal of Psychology, 85, 541-544.

Haidt, J., McCauley, C., \& Rozin, P. (1994). Individual differences in sensitivity to disgust: a scale sampling seven domains of disgust elicitors. Personality and Individual Differences, 16, 701-713.

Hayslett, M. M., \& Wildemuth, B. M. (2004). Pixels or pencils? The relative effectiveness of Web-based versus paper surveys. Library \& Information Science Research, 26, 73-93.

Himle, J. A., McPhee, K., Cameron, O. G., \& Curtis, G. C. (1989). Simple phobia: evidence for heterogeneity. Psychiatry Research, $28,25-30$.

van Hout, W. J. P. J., \& Bouman, T. K. (2006). Clinical features of emetophobia (fear of vomiting): prevalence and comorbidity. Manuscript submitted for publication.

van Hout, W. J. P. J. , Oude Lansink, P., \& Bouman, T. K. (2005). De fenomenologie en comorbiditeit van emetofobie (angst voor overgeven). Gedragstherapie, 38, 49-64.

de Jong, P. J., \& Muris, P. (2002). Spider phobia: interaction of disgust and perceived likelihood of involuntary physical contact. Journal of Anxiety Disorders, 16, 51-65.

de Jong, P. J., Peters, M. L., \& Vanderhallen, I. (2002). Disgust and disgust sensitivity in spider phobia: facial EMG in response to spider and oral disgust imagery. Journal of Anxiety Disorders, 16, $477-493$.

Lelliott, P., McNamee, G., \& Marks, I. (1991). Features of agora-, social, and related phobias and validation of the diagnoses. Journal of Anxiety Disorders, 5, 313-322.

Lipsitz, J. D., Fyer, A. J., Paterniti, A., \& Klein, D. F. (2001). Emetophobia: preliminary results of an internet survey. Depression and Anxiety, 14, 149-152.

Lydiard, R. B., Laraia, M. T., Howell, E. F., \& Ballenger, J. C. (1986). Can panic disorder present as irritable bowel syndrome? Journal of Clinical Psychiatry, 47, 470-472.
Marks, L. M. (1987). Fears, phobias and rituals. New York: Oxford University Press.

Massop, M. (2005). Misselijk van angst; leven met een overgeeffobie. Houtekiet: Antwerpen.

Matchett, G., \& Davey, G. C. L. (1991). A test of disease-avoidance model of animal phobias. Behaviour Research and Therapy, 29, 91-94.

Moran, D. J., \& O’Brien, R. M. (2005). Competence imagery: a case study treating emetophobia. Psychological Reports, 96, 635-636.

Mulkens, S. A. N., de Jong, P. J., \& Merckelbach, H. (1996). Disgust and spider phobia. Journal of Abnormal Psychology, 105, 464468.

Olatunji, B. O., Arrindell, W. A., \& Lohr, J. M. (2005a). Can the sex differences in disgust sensitivity account for the sex differences in blood-injection-injury fears? Personality and Individual Differences, 39, 61-71.

Olatunji, B. O., Sawchuk, C. N., Arrindell, W. A., \& Lohr, J. M. (2005b). Disgust sensitivity as a mediator of the sex differences in contamination fears. Personality and Individual Differences, 38, 713-722.

van Overveld, W. J. M., de Jong, P. J., Peters, M. L., Cavanagh, K., \& Davey, G. C. L. (2006). Disgust propensity and disgust sensitivity: separate constructs that are differentially related to specific fears. Personality and Individual Differences, 41, 1241-1252.

Philips, H. C. (1985). Return of fear in the treatment of a fear of vomiting. Behaviour Research and Therapy, 23, 45-53.

Pollard, C. A., Tait, R. C., Meldrum, D., Dubinsky, I. H., \& Gall, J. S. (1996). Agoraphobia without panic: case illustrations of an overlooked syndrome. The Journal of Nervous and Mental Diseases, 184, 61-62.

Ritow, J. K. (1979). Brief treatment of a vomiting phobia. The American Journal of Clinical Hypnosis, 21, 293-494.

Rozin, P., Fallon, A. E., \& Mandell, R. (1984). Family resemblance in attitudes to food. Developmental Psychology, 20, 309-314.

Rozin, P., Haidt, J., \& McCauley, C. R. (2000). Disgust. In: M. Lewis \& J. M. Haviland Jones (Eds.), Handbook of emotions (2nd ed., pp. 637-652). New York: Guilford Press.

Thorpe, S., \& Salkovskis, P. M. (1998). Studies on the role of disgust in the acquisition and maintenance of specific phobias. Behaviour Research and Therapy, 36, 877-893.

Veale, D., \& Lambrou, C. (2006). The psychopathology of vomit phobia. Behavioural and Cognitive Psychotherapy, 34, 139150.

Ware, J., Jain, K., Burgess, I., \& Davey, G. C. L. (1994). Diseaseavoidance model: factor analysis of common animal fears. Behaviour Research and Therapy, 32, 57-63. 